\title{
O PROGRAMA BANDEIRA AZUL DE CERTIFICAÇÃO PARA PRAIAS NA PERCEPÇÃO DOS GESTORES NACIONAIS DOS PAÍSES PARTICIPANTES
}

\author{
THE BLUE FLAG BEACH CERTIFICATION PROGRAM IN THE PERCEPTIONS OF \\ NATIONAL MANAGERS OF THE PARTICIPATING BEACHES
}

\author{
EL PROGRAMA BANDERA AZUL DE CERTIFICACIÓN PARA PLAYAS EN LA \\ PERCEPCIÓN DE LOS GESTORES NACIONALES DE LOS PAÍSES PARTICIPANTES
}

Leana Paula Bernardi

Diretora Técnica do Instituto Ambiental em Redes, Florianópolis/ SC e Coordenadora Nacional do Programa Bandeira Azul no Brasil iar@iarbrasil.org.br

\section{Paulo dos Santos Pires}

Docente e Pesquisador do Curso de Graduação e do Programa de Pós Graduação em Turismo e Hotelaria da Universidade do Vale do Itajaí-SC

pires@univali.br

Data de Submissão: 02/05/2014

Data de Aprovação: 13/09/2015

RESUMO: O tema central deste estudo é o Programa Bandeira Azul de Certificação para praias, que desde 1987 promove melhores práticas na gestão costeira em países de todos os continentes. O programa de certificação ambiental Bandeira Azul é um modelo de grande importância para o turismo nacional, uma vez que coloca as praias certificadas em um patamar de excelência que as diferencia das demais. Com isso, o objetivo do estudo foi conhecer os benefícios ambientais, sociais e econômicos percebidos com a implantação deste programa nos países participantes. Adotou-se a pesquisa de nível exploratório e descritivo, com abordagem qualitativa e quantitativa de caráter não probabilístico. A pesquisa de campo ocorreu com a aplicação de questionários junto aos operadores nacionais dos países que desenvolvem o programa. A análise dos resultados foi 
conduzida pelos preceitos do Programa Bandeira Azul, no contexto da sustentabilidade no turismo, do gerenciamento costeiro e da certificação ambiental. Em meio ao conjunto dos resultados, constatou-se que os operadores nacionais mantêm uma visão positiva e entusiasta, pela qual, mesmo admitindo dificuldades, garantem que a certificação traz benefícios ambientais, sociais e econômicos importantes e que devem ser considerados pelos gestores municipais e possíveis patrocinadores do programa.

Palavras chave: Turismo de sol e praia. Programa Bandeira Azul. Sustentabilidade do Turismo.

ABSTRACT: The central theme of this study is the Blue Flag beach certification program, set up in 1987 to promote better practices in the coastal management of beaches on all continents. The Blue Flag beach certification program is an important model for national tourism, as it puts the certified beaches on a level of excellence that differentiates them from other beaches. The objective of the study was to investigate the perceived environmental, social and economic benefits of the implementation of this program in the participating countries. An exploratory and descriptive study was adopted, with a qualitative and quantitative, non-probabilistic approach. Field research was carried out with the application of questionnaires with national operators in the countries where the program is operating. The results were analyzed based on the precepts of the Blue Flag Program, in the context of sustainability in tourism, coastal management, and environmental certification. Among the results, it was found that the National Operators maintain a positive and enthusiastic vision, whereby even though they admit difficulties, they guarantee that it brings important environmental, social and economic benefits that should be considered by municipal managers and possible sponsors of the program.

Keywords: Sun, sea and sand tourism. Blue Flag Program. Tourism Sustainability.

RESUMEN: El tema central de este estudio es el Programa Bandera Azul de Certificación para playas, que desde 1987 promueve mejores prácticas en la gestión costera en países de todos los continentes. El programa de certificación ambiental Bandera Azul es un modelo de gran importancia para el turismo nacional, puesto que coloca a las playas certificadas en un nivel de excelencia que las distingue de las demás. De este modo, el objetivo del estudio fue conocer los beneficios ambientales, sociales y económicos percibidos con la implantación de este programa en los países participantes. Se adoptó la investigación de nivel exploratorio y descriptivo, con abordaje cualitativo y cuantitativo de carácter no probabilístico. La investigación de campo se llevó a cabo con la aplicación de cuestionarios a los operadores nacionales de los países que desarrollan el programa. El análisis de los resultados fue conducido mediante los preceptos del Programa Bandera Azul, en el contexto de la sostenibilidad en el turismo, del gerenciamiento costero y de la certificación ambiental. En medio del conjunto de los resultados se constató que los operadores nacionales mantienen una visión positiva y entusiasta por la cual, incluso admitiendo dificultades, garantizan que la certificación trae beneficios ambientales, sociales y económicos importantes y que deben ser considerados por los gestores municipales y posibles patrocinadores del programa.

Palabras clave: Turismo de sol y playa. Programa Bandera Azul. Sostenibilidad del Turismo. 
atividade turística representa cerca de 5\% do PIB e 6\% das ofertas
de emprego nos países reunidos no chamado G20 (Grupo dos 20),
a soma dos valores da exportação mundial dos serviços turísticos gera em torno de US\$3.000 milhões ao dia (OMT, 2012). Com isso, o turismo assume papel relevante na economia mundial e garantir a sua sustentabilidade é o grande desafio dos profissionais, governantes e comunidades envolvidas.

Pelo lado da demanda turística, a sustentabilidade, em boa parte, corresponde a uma expectativa de ambientes íntegros e limpos, recursos naturais atraentes, tradições históricas e culturais autênticas e pessoas acolhedoras, conforme atestam o PNUMA e a OMT (2006). Assim, o trade turístico observa o surgimento de um novo público consumidor mais consciente da sua relação com o ambiente. Consequentemente este consumidor passa a optar por destinos, atividades e bens mais sustentáveis e a buscar por produtos e serviços comprometidos com o meio ambiente e a qualidade de vida.

Com base nesta realidade, visando nortear o desenvolvimento dos destinos de sol e praia e premiar seu bom desempenho ambiental, surgiram sistemas de gestão socioambiental. Alguns desses programas fornecem mecanismos de gestão e outros certificam a infraestrutura e a gestão de praias. Estas certificações sinalizam para o consumidor que o destino cumpre normas e critérios preestabelecidos e, assim, tem o direito de ostentar um selo de qualidade que pode trazer a ele maior visibilidade nacional e internacional (BRASIL, 2009).

Em se tratando de destinos de sol e praia, destaca-se o Programa Bandeira Azul (Blue Flag) de certificação de praias e marinas. A sua difusão mundial e credibilidade conferem um status de reconhecimento internacional de grande importância para o trade turístico. Uma "praia Bandeira Azul" deve atender às exigências em relação à qualidade da água de banho, limpeza da praia, banheiros, segurança, informação e educação ambiental, acessos ordenados e seguros, entre outros. Ao conquistar um selo de certificação de qualidade ambiental internacional, um destino atrairá visibilidade aumentando a quantidade e a qualidade de seus visitantes. 
Esses programas e normas salientam a necessidade de adaptação dos equipamentos turísticos para a valorização da paisagem e das características culturais existentes, sempre em consonância com a legislação ambiental e patrimonial. Uma norma ou certificação deve prever e prezar pelas necessidades de segurança e acessibilidade dos turistas e dos usuários locais; pela excelência da qualidade da água de banho; além de fomentar a utilização de sistemas de gestão ambiental desenvolvidos de uma maneira participativa com os setores da sociedade. No caso do Programa Bandeira Azul e de seu funcionamento nos países onde está implantado, ainda não se há um conhecimento amplo dos benefícios alcançados, bem como não se dispõe de elementos para a comparação e discussão entre as distintas situações relacionadas a cada realidade do programa em nível nacional. É este o problema que motivou o desenvolvimento da presente pesquisa e que teve, então, por objetivo conhecer os benefícios sociais, econômicos e ambientais percebidos como resultado da certificação Bandeira Azul pelos gestores do programa nos países onde atualmente ele é desenvolvido.

Portanto, a relevância empírica desta pesquisa reside em contribuir para o preenchimento de lacunas de conhecimento sobre o funcionamento deste programa em âmbito internacional e, assim sendo, a investigação deste tema possui o potencial de expandir a discussão em torno da gestão de destinos turísticos de sol e praia e, com isso, trazer mais informações sobre os benefícios ambientais, econômicos e sociais da certificação de praias. Desta forma, tais informações se constituirão em argumentos para incentivar gestores municipais e empresários a investirem financeira e politicamente na busca pela certificação Bandeira Azul. A indisponibilidade de informações que auxiliem na avaliação dos resultados desta certificação na atualidade é confirmada pela própria coordenadora internacional do Programa Bandeira Azul, Sophie Bachet, que em contato informal em outubro de $2012^{1}$, admitiu que a própria Foundation for Environmental Education (FEE) não possui uma base de dados deste tipo que possa demonstrar quantitativa e qualitativamente os benefícios do programa.

Metodologicamente desenvolveu-se uma pesquisa em nível exploratório e descritivo, com abordagem qualitativa e quantitativa com procedimento 1 Referente ao encontro pessoal entre um dos autores do presente estudo e esta pessoa, ocorrido por ocasião da reunião anual do Programa Bandeira Azul em outubro de 2012 no município de Tenby, no País de Gales. 
amostral não probabilístico. Além do levantamento em fontes bibliográficas e documentais, foram coletados dados primários por meio de um questionário estruturado e direcionado aos Operadores Nacionais de todos os 48 países que desenvolvem o programa. Efetivamente o questionário foi preenchido pelos 29 representantes de cada país participante da reunião anual do Programa Bandeira Azul, ocorrida em outubro de 2012 no município de Tenby, no País de Gales. Alternativamente, o mesmo questionário foi enviado por correio eletrônico para os demais representantes que não estavam presentes, apor meio do website surveymonkey (http://www.surveymonkey.com/s/BTWRJFS) tendo sido respondidos 04 questionários.

Considerando a abrangência global do tema, enfocaram-se as dificuldades e os benefícios na gestão do programa percebidos em cada país. Dessa forma, as perguntas foram formuladas levando em consideração os quatro temas principais que compõem os critérios do programa (educação ambiental, equipamentos e serviços, qualidade da água e gestão ambiental). A análise dos resultados foi feita com base nos princípios sociais, econômicos e ambientais que norteiam os critérios dao Bandeira Azul. Agregou-se a estes resultados uma abordagem com base também documental, relativa ao tempo de participação dos países no programa e à sua distribuição continental, à evolução da outorga de bandeiras azuis no mundo e à exposição das dificuldades enfrentadas nos diferentes países para o crescimento do programa.

As próximas seções, 2 e 3, contêm o aporte teórico pertinente ao campo temático abordado, e a seção 4 representa o resultado empírico propriamente dito da pesquisa realizada junto aos operadores nacionais do programa.

\section{PRESSUPOSTOS DO DESENVOLVIMENTO DE DESTINOS} TURÍSTICOS

O crescimento nos índices de viagens evidencia o surgimento de novos mercados emissores e receptores, além de uma renovação no perfil dos viajantes na busca por qualidade dos produtos turísticos. Assim, segundo o Center for Responsible Travel, o trade e os consumidores tendem a reconhecer a importância 
de viagens responsáveis que minimizam os impactos negativos, trazem benefícios econômicos às comunidades anfitriãs e preservam os recursos naturais e culturais dos destinos (CREST, 2013). Advém daí a atenção crescente com a reputação de um destino no que tange à sua responsabilidade social e ambiental. Verifica-se, também, que esta tendência é, na mesma intensidade, observada em diversos países com diferentes graus de desenvolvimento turístico.

Por outro lado, Choi e Sirakaya (2006) ponderam que, ao perceber as desvantagens do turismo de massa, os gestores passaram a procurar opções alternativas de desenvolvimento, planejamento e gestão do turismo. O principal desafio da gestão do turismo então é alcançar o equilíbrio entre crescimento econômico, proteção/preservação ambiental e justiça social (REBOLLO; BAIDAL, 2003). Neste contexto, os planejadores envolvidos com o desenvolvimento de destinos turísticos, conforme observam Lai, Li e Feng (2006), devem balancear suas concepções profissionais com as reais necessidades e os anseios do local, para que não se crie um abismo entre o planejado e a realidade. Nesta mesma linha, Kaupilla, Saarinen e Leinonen (2009) asseveram que planejar, para um turismo sustentável, é fortalecer e desenvolver a comunidade e a sua economia, salvaguardando o meio ambiente.

Para Hall (2004), a exigência de um planejamento público em turismo só começou a acontecer em função das mudanças percebidas no mercado turístico, assim como pelas respostas do governo aos problemas de reestruturação econômica nas áreas urbana e rural. Com o aumento na concorrência, os destinos turísticos procuraram melhorar seus atrativos e infraestruturas, a fim de continuar conquistando mais visitantes ou, simplesmente, para aumentar o ciclo de vida do seu produto. Como se sabe, a infraestrutura básica de um produto turístico é aquela normalmente utilizada pelos habitantes do destino, mas que serve de suporte para os turistas, como as estradas, a iluminação, os bens públicos de maneira geral, o comércio, etc. Já a infraestrutura turística é aquela mais voltada à atividade turística propriamente dita, como os hotéis, meios de transporte, aeroportos, etc. (LEMOS, 2005).

Associado à infraestrutura, o investimento na prestação de serviços com qualidade superior tornou-se uma estratégia competitiva para a diferenciação de produtos turísticos, devendo ser conduzido pelos planejadores e gestores de 
destinos turísticos, em meio à crescente oferta de novos produtos (GÂNDARA et al., 2012). Este pressuposto respalda a preocupação com a qualidade dos empreendimentos, condição esta essencial para o sucesso na atividade turística, de acordo com Ruschmann, Rosa e Weidgenant (2010).

As áreas costeiras, segundo Ariza et al. (2008), são reconhecidamente importantes destinos turísticos e são sempre submetidas a uma pressão adicional, principalmente quando o estabelecimento das condições para o lazer nestas áreas se torna parte da economia local. Assim, uma vez que o turismo tem nas praias a base de sua atratividade, a gestão costeira deverá se adaptar a esta utilização. Por fim, Fonteles (2004) considera que encontrar estratégias para melhor gerir espaços naturais é uma tarefa de todos os atores sociais, em cujo âmbito o planejamento e a gestão dos destinos turísticos de sol e praia devem ser concebidos com a maior participação possível da sociedade.

\section{A CERTIFICAÇÃO NO TURISMO E O PROGRAMA BANDEIRA AZUL}

Os selos ecológicos, conforme Welford (1995), têm sido idealizados em inúmeros países basicamente numa tentativa de promover o uso de métodos de produção menos destrutivos ao meio ambiente, por meio de esquemas independentes de reconhecimento do perfil ambiental positivo de um produto. Por sua vez, Buckley (2002) considera o que chama de rótulos ecológicos no turismo muito comuns, porém descoordenados, por serem criados tanto por empresas individuais como por associações industriais, organizações de voluntários e agências governamentais, cuja aplicação varia desde a escala de localidade até a escala global, ou desde atividades individuais até destinos como um todo, incluindo distintas modalidades, tais como códigos voluntários, prêmios, acreditação e sistemas de certificação.

O WWF (2001b) constatou mais de 250 tipos de mecanismos de certificação (prêmios e selos) no mundo, que atestam a qualidade de produtos e de serviços de turismo. A mesma fonte comenta que esta disseminação evidencia o interesse em transformar o turismo em uma atividade sustentável, mas também pode e costuma gerar descrédito e confusão no mercado consumidor e investidor, pois muitas vezes a certificação é utilizada muito mais como 
ferramenta de marketing do que como compromisso socioambiental. Por sua vez, a International Tourism Society considera que a certificação é uma forma de garantir que uma atividade ou um produto atende a determinados padrões, sendo que no turismo existem três tipos comuns de certificação: de qualidade, para todo o mercado de turismo; de sustentabilidade, também para todos os setores; e de ecoturismo voltado para o turismo sustentável que ocorre em ecossistemas naturais, protegidos ou frágeis (BIEN, 2003).

Já para a Rainforest Alliance, organização internacional de conservação ambiental responsável pela coordenação das operações do STCNA (Sustainable Tourism Certification Network of the Americas), a certificação pode ser definida como:

(...) a market-based tool. It links players in the value chain by guaranteeing, or certifying, to users (tourists and tourism intermediaries) that the suppliers (tourism providers) adhere to a specific set of standards and indicators of sustainable practices. (RAINFOREST ALLIANCE, 2012, p. 4).

Ou seja, a certificação é uma ferramenta de mercado que liga os usuários (demanda turística) aos fornecedores (oferta turística), assegurando que estes adiram a um conjunto específico de normas e indicadores de práticas sustentáveis. Analogamente, uma certificação ambiental deverá garantir aos consumidores que um determinado produto por eles consumido é resultado de práticas realizadas com critérios ecológicos, econômicos e sociais.

A mesma fonte atesta que um selo de certificação confere confiabilidade e segurança entre os envolvidos no mercado, além de representar um mecanismo de divulgação e marketing do produto ou do serviço certificado. Em reforço, Buckley (1999) afirma que certificação ambiental eficaz é aquela que é relevante para o mercado e seus clientes, com critérios adequados que verificam serviços ou destinos de turismo, permitindo que estes sejam testados e auditados regularmente para verificar o seu desempenho e, se necessário, para descredenciar estabelecimentos que descumpram os objetivos e os critérios do selo diante da globalização e do crescimento turístico em locais remotos.

Para Creo e Fraboni (2011), os programas voluntários de certificação no turismo possuem duas funções muito importantes, ao direcionar os turistas para locais ambientalmente responsáveis e as empresas para o desafio da 
promoção de melhorias e de novas normas ambientais no domínio do turismo sustentável. Neste contexto, o Programa Bandeira Azul se constitui em uma certificação voluntária, conforme destacam Lucrezi et al. (2015), adotada para o gerenciamento de praias e para a atração de turistas. Como enfoque central da presente abordagem, expõem-se a seguir os antecedentes e a configuração atual deste programa.

O Programa Bandeira Azul nasceu na França em 1985, tendo como base critérios de tratamento de esgoto e qualidade de água de banho. Em 1987, a ideia básica do programa foi apresentada para a instituição então conhecida como FEEE - Foundation for Environmental Education of Europe, que o acolheu e iniciou a sua expansão na Europa. Inicialmente, a FEEE era composta por apenas quatro países: Espanha, França, Alemanha e Dinamarca. Contudo, quando a proposta do Bandeira Azul foi lançada na instituição, dez países europeus já estavam engajados (FEE, 2012).

Em meados dos anos 1990, a FEEE percebeu um aumento no interesse no Programa Bandeira Azul por parte de países não europeus. Este interesse se confirmou quando a Espanha e a França foram procuradas pela Organização Mundial do Turismo e pelo Programa das Nações Unidas para o Meio Ambiente, a fim de que se desenvolvesse um manual sobre gerenciamento costeiro, tendo como base os critérios adotados pelo Programa Bandeira Azul.

A África do Sul, em 2001, se tornou o primeiro país fora da Europa a integrar a FEEE que, assim, perdeu então em sua sigla o último "E" de "Europa", tornando-se simplesmente FEE (Foundation for Environmental Education). A coordenação do programa foi inicialmente sediada na França até 1988, durante o ano de 1989 na Holanda e desde 1990 a sua coordenação é sediada na Dinamarca (FEE, 2012). No ano de 2015 o Programa Bandeira Azul completa vinte e oito anos de resultados progressivos. Segundo a Asociación de Educación Ambiental y Del Consumidor ADEAC (2013), em 1987, no primeiro ano de existência do Programa, 10 países participaram e certificaram 244 praias e 208 marinas. Atualmente o programa contabiliza a participação de 49 países no continente europeu e na África do Sul, Marrocos, Tunísia, Nova Zelândia, Brasil, Canadá e Caribe, contemplando mais de 4000 praias e marinas certificadas (BLUE FLAG, 2015). Basicamente, a operacionalização do programa envolve os agentes apresentados no Quadro 1. 
Quadro 1: Agentes de operacionalização do Programa Bandeira Azul

\begin{tabular}{|c|c|}
\hline $\begin{array}{l}\text { Operador Internacional } \\
\text { Foundation for the } \\
\text { Environmental Education - } \\
\text { FEE }\end{array}$ & $\begin{array}{l}\text { É a instituição que detém todos os direitos internacionais sobre o } \\
\text { Programa Bandeira Azul e é responsável pela articulação do Júri } \\
\text { Internacional. A FEE, sediada na Dinamarca, é uma organização não } \\
\text { governamental internacional e sem fins lucrativos que promove } \\
\text { educação ambiental para o desenvolvimento sustentável. }\end{array}$ \\
\hline Operador Nacional & $\begin{array}{l}\text { As organizações da sociedade civil de interesse público credenciadas } \\
\text { em cada país. No Brasil, o operador é o Instituto Ambiental Ratones } \\
\text { (IAR). }\end{array}$ \\
\hline $\begin{array}{l}\text { Agente Promotor } \\
\text { Organizações da Sociedade } \\
\text { Civil locais }\end{array}$ & $\begin{array}{l}\text { São organizações não governamentais locais dispostas a promover o } \\
\text { Programa Bandeira Azul e a fiscalizar as praias certificadas. } \\
\text { Estas devem se cadastrar junto ao operador nacional para obterem os } \\
\text { direitos de representar o programa em determinada região. }\end{array}$ \\
\hline $\begin{array}{l}\text { Agente Local } \\
\text { Organizações da Sociedade } \\
\text { Civil e poder público }\end{array}$ & $\begin{array}{l}\text { Prefeitura Municipal e um grande número de atores indiretamente } \\
\text { envolvidos, representando os vários segmentos da Sociedade Civil } \\
\text { (moradores, iniciativa privada, empreendedores, comunidades } \\
\text { tradicionais e todas as demais associações comunitárias). }\end{array}$ \\
\hline
\end{tabular}

Fonte: IAR (2012).

Já os critérios de avaliação do Programa Bandeira Azul estão distribuídos em quatro temas principais, que são: educação e informação ambiental; qualidade da água; gestão ambiental; e segurança dos usuários. Os "Operadores Nacionais" são as instituições responsáveis pelo programa em cada um dos países membros da FEE. Para desenvolver os programas, cada país pode inscrever uma instituição não governamental que será a representante exclusiva de todos os programas da FEE em seu país. No Brasil, por exemplo, o Operador Nacional desde 2006 é o Instituto Ambiental Ratones, com sede na cidade de Florianópolis - SC.

\section{RESULTADOS E DISCUSSÃO DA PESQUISA COM OS OPERADORES NACIONAIS}

Como já informado, o levantamento de dados sobre as dificuldades e os benefícios da implantação do Programa Bandeira Azul em seus respectivos países ocorreu com a aplicação de um questionário junto aos operadores nacionais do programa. Em 2011, a FEE realizou uma pesquisa similar com os gestores das praias. A pesquisa foi denominada Blue Flag 2011 Survey for Beach 
and Marina Managers. Foram entrevistados $80 \%$ dos representantes das praias, além das marinas certificadas de todos os países participantes do programa. Esta pesquisa intencionava verificar os benefícios da certificação Bandeira Azul (IAR, 2012). Muitos dos questionamentos levantados em 2011 pela FEE têm resultados similares aos coletados no presente estudo e serão mencionados no decorrer da análise. Dessa forma, os resultados apresentados a seguir enfocarão os benefícios ambientais, sociais e econômicos da certificação e sua relação com a pesquisa da FEE em 2011.

A distribuição geográfica dos 29 países participantes da pesquisa (barra azul) representa proporcionalmente a mesma distribuição observada na totalidade dos 46 países que são membros da FEE (Gráfico 01).

Gráfico 01: Localização continental dos países

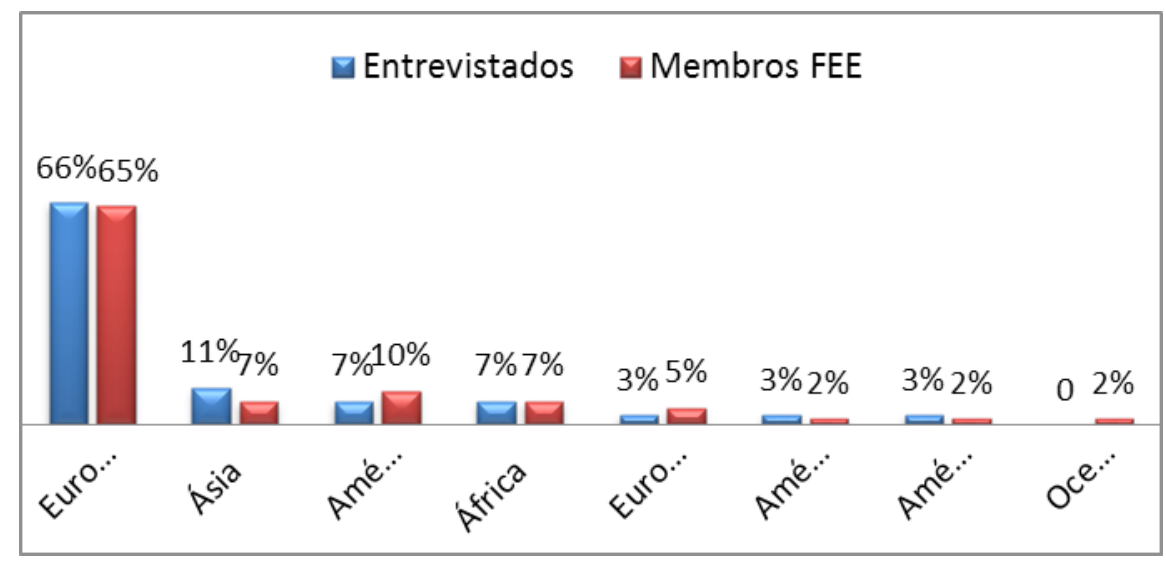

Fonte: Autores (2013).

Constata-se no Gráfico 01 que o continente mais representativo é a Europa, com 66\% dos países; seguido da Ásia, com 11\%; e da América Central e da África, ambas com $7 \%$.

Quanto à longevidade do programa (Gráfico 2), destacam-se três grupos, respectivamente, 25 anos ou mais, correspondente a $24 \%$ dos países; até 20 anos, correspondente a 21\%; e até 15 anos, correspondente a 14\% dos países. Salienta-se que, segundo a FEE (2012), os primeiros 10 anos do programa foram financiados substancialmente pela União Europeia, o que garantiu uma boa estrutura para a expansão e, principalmente, para a consolidação do programa na Europa. 
Gráfico 02: Tempo de participação dos países no programa

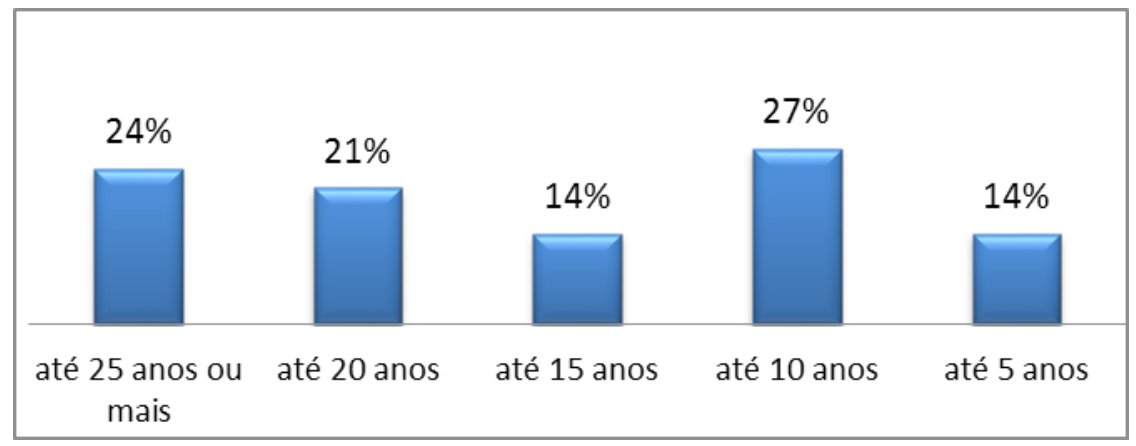

Fonte: Autores (2013).

Os países que participam do programa há até 10 anos (27\%) configuram o grupo com a distribuição geográfica mais variada, o que, provavelmente, reflete o resultado imediato da internacionalização do programa, ocorrida em 2001, quando se observou um período de expansão mundial. Foi neste período que muitos países iniciaram sua campanha Bandeira Azul.

Os países cujos representantes responderam à pesquisa e que participam do programa há menos de cinco anos representam 14\% do total. Destes, 75\% são procedentes da Ásia e 25\% são europeus. Estes dados refletem uma estabilização no crescimento do programa e a manutenção da predominância dos países europeus, que, mesmo ainda sendo a maioria, continua a aumentar, contudo em uma proporção menor que os de outros continentes. Adicionalmente, estes dados confirmam o grande potencial de crescimento reservado para os próximos anos. As Américas, a Oceania e a África ainda têm uma participação muito pequena, mas com tendência ao ingresso de novos países.

A evolução do programa pode ser observada no Gráfico 3, elaborado pela Associação Bandeira Azul da Europa (ABAE), instituição responsável pelo programa em Portugal. Nesta representação, pode-se verificar que a quantidade de praias certificadas tem apresentado uma média de crescimento contínuo, condizente com a progressão do número de países participantes. 
Gráfico 3: Evolução do número de Bandeiras Azuis no mundo (1987- 2011)

\section{Evolução do Número de Bandeiras Azuis no Mundo 1987-2011}

(em 2012 no hemisfério Norte foram atribuídas 3098 BA a praias e 646 Marinas)

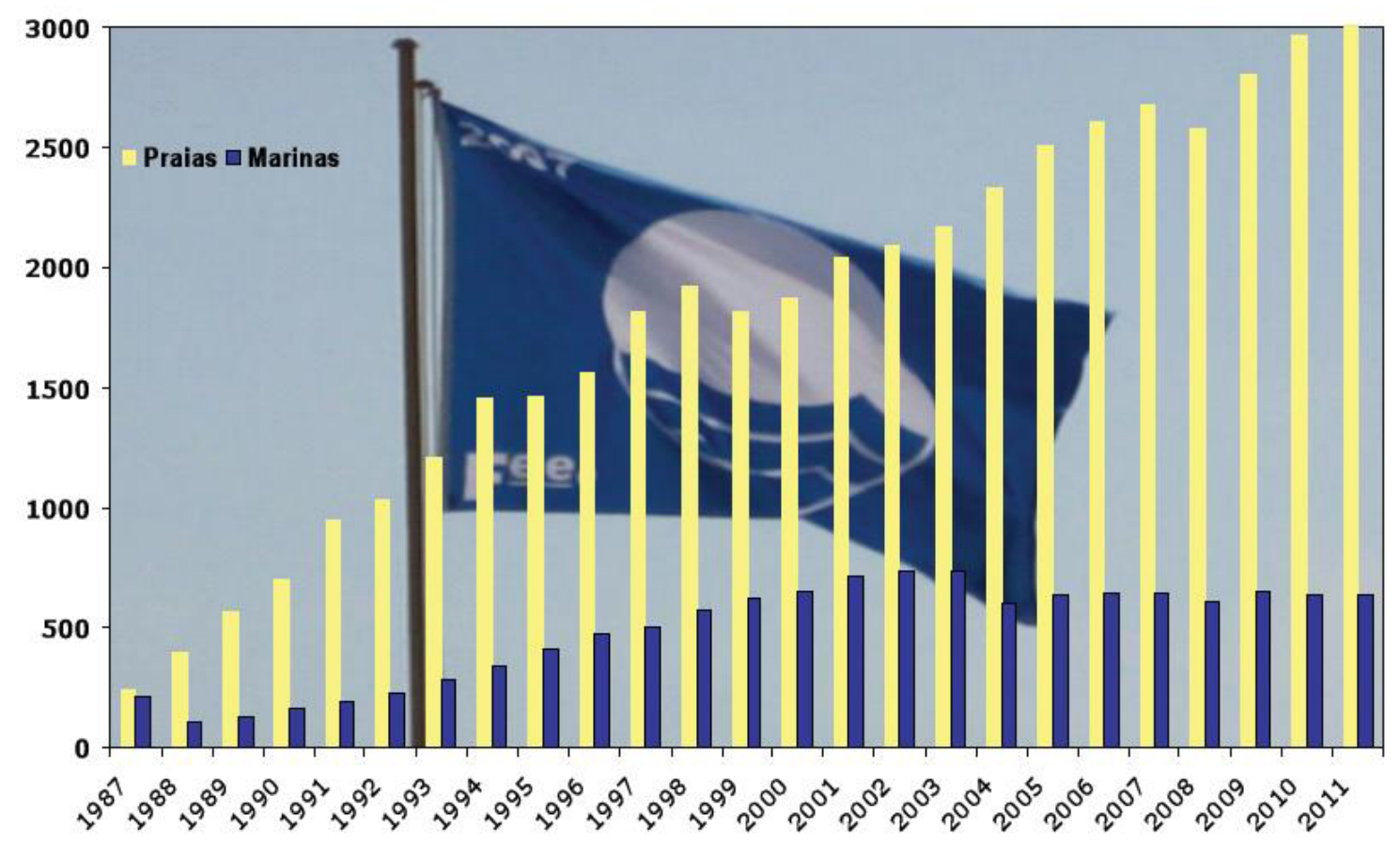

Fonte: ABAE (2012).

Na medida em que o programa cresce e passa a abranger um número maior de países, verifica-se também um crescimento proporcional ou até maior no número de praias e marinas certificadas. Os números do crescimento mostram que, desde sua origem em 1987, quando foram certificadas 244 praias, até o primeiro semestre de 2013, quando se totalizaram 3201 praias, houve um crescimento muito expressivo.

Comprovando esta tendência para o ano de 2012, em relação ao total de bandeiras concedidas e/ou renovadas para cada um dos 29 países representados na pesquisa, observa-se que os cinco países a apresentarem uma quantidade superior de bandeiras concedidas em 2012 (entre 275 e 540 praias) foram Turquia, Grécia, Portugal, França e Espanha. Destes, o tempo de desenvolvimento do 
programa na Turquia é de 19 anos e, na Grécia, 20 anos. Os outros três países desenvolvem o programa desde o início (1987), o que os torna mais experientes e explica a sua superioridade no número de Bandeiras Azuis concedidas.

Ainda, entre estes cinco países com maior número de bandeiras, deve-se destacar o caso da Espanha, que tem todo o programa financiado pelo seu governo federal, pois este reconhece, na certificação Bandeira Azul, um grande benefício para impulsionar o turismo no país. Há também um segundo grupo de seis países com um número menor, mas também expressivo, de praias certificadas (entre 40 e 110 praias). São eles: Croácia, Chipre, Irlanda, Inglaterra Holanda e Alemanha. Neste grupo, igualmente observam-se países que desenvolvem o programa há pelo menos 15 anos. Portanto, é notável a relação entre a obtenção de bandeiras e o tempo de desenvolvimento do programa pelo país.

O grupo de países com uma quantidade menor (entre 10 e 30 praias) é composto por $72 \%$ de países que ingressaram no programa nos últimos 5 a 10 anos e, ainda, por $57 \%$ de países de fora da Europa, entre eles, Tunísia, República Dominicana, Canadá, África do Sul. Este panorama demonstra que ainda há um bom potencial de crescimento para o programa nestes países. Existe também um grupo de países com um número bastante baixo de praias certificadas (até 8 praias), que são os países que ingressaram no programa há menos tempo, como Jordânia, Emirados Árabes, Brasil, Porto Rico, Lituânia e Escócia.

Tal a importância da certificação de praias pelo Programa Bandeira Azul para alguns países que durante a reunião anual dos Operadores Nacionais do Bandeira Azul de 2012, em Tenby, País de Gales, a coordenadora do programa na Espanha declarou que as agências de viagem de seu país somente divulgam os pacotes e os roteiros para a próxima temporada após a divulgação dos resultados da certificação Bandeira Azul. Isto significa que, se a praia perder a certificação, ela sai automaticamente do circuito e acaba perdendo visitantes de maneira bastante expressiva. É o que também afirma Font (2002), para quem o Bandeira Azul significa algo e tem um impacto na escolha do destino e, por outro lado, não ter também significa que a praia não cumpre padrões.

Por sua vez, a pesquisa Blue Flag Survey de 2011 destacou que $80 \%$ dos respondentes consideram que o Programa Bandeira Azul impulsiona melhorias e incentiva positivamente nas tomadas de decisão dos municípios. A maioria 
dos respondentes declarou ainda que a certificação colabora para a conquista de financiamento para obras de infraestrutura, ou seja, ela é percebida como um incentivo à melhora na qualidade ambiental (BLUE FLAG, 2011).

Quanto à origem dos recursos financeiros e à sua influência no crescimento do programa em diferentes países, tem-se um panorama em que as taxas cobradas de cada candidato pelo operador nacional de seu país e o auxílio governamental foram declarados como as principais fontes de recursos, evidenciando-se que a garantia de recursos viabiliza o desenvolvimento e a gestão do programa e explica as diferenças na quantidade de praias e marinas certificadas.

Dos 29 países que participaram da pesquisa, 45\% têm seu orçamento coberto por fontes mistas e $55 \%$ conseguem a totalidade de seus recursos oriundos de uma fonte única. Destes, 31\% são mantidos com recursos governamentais, $6 \%$ com investimento de multinacionais, $6 \%$ com o auxílio de empresas nacionais e $57 \%$ trabalham basicamente dos recursos levantados com as taxas do programa oriundas da contribuição anual dos municípios.

Irlanda, Tunísia, Porto Rico, Montenegro e Espanha são os países que desenvolvem suas atividades com $100 \%$ de recursos oriundos do governo. Já os Emirados Árabes têm $100 \%$ dos seus recursos garantidos por empresas multinacionais e a República Dominicana capta $100 \%$ dos seus recursos em empresas nacionais, mais especificamente, empresas do ramo hoteleiro.

Diferentes economias refletem distintos interesses e motivações para justificar o financiamento do programa, sendo que, na maioria das vezes, a motivação é o incremento do turismo responsável e a proteção ambiental. Segundo Araujo (2008), o grande mote da certificação ambiental é o de que, atualmente, não basta oferecer ao turista apenas sol, mar e areia, mas também permitir que ele seja servido por empresas que tenham uma postura positiva em relação à proteção do meio ambiente. Isto incentiva as empresas a investir no Programa Bandeira Azul, para assim se beneficiarem da boa imagem e da credibilidade associadas a ele.

Ao investigar as maiores dificuldades enfrentadas nos diferentes países para o crescimento do programa, por meio do Gráfico 4 se identifica, em primeiro lugar, as dificuldades financeiras e, em segundo lugar, a falta de vontade política. 
As dificuldades financeiras são um fator limitante por tratar-se de um programa que se renova anualmente e no qual as taxas são recolhidas uma única vez junto ao agente financiador (governos ou empresas). Assim sendo, a taxa deve ser administrada para a manutenção do trabalho e da equipe durante o ano todo. A temporada de apenas três meses, na maioria dos países, acaba tornando o programa pouco atrativo para potenciais patrocinadores.

Gráfico 04: Média geral das dificuldade

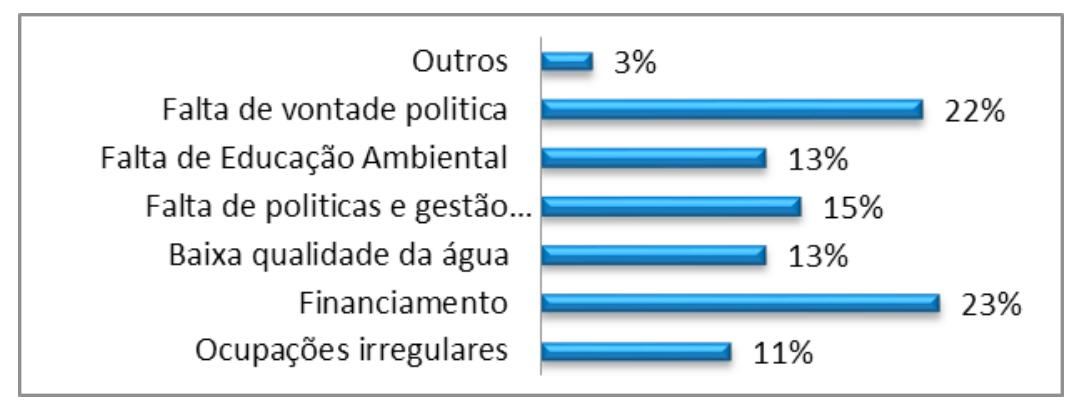

Fonte: Autores (2013).

Nota-se também que a falta de vontade política é fator limitante na maioria dos países, porque são as prefeituras municipais que devem inscrever as praias e garantir os serviços necessários para a manutenção do padrão exigido. Muitas vezes, este não é o objetivo principal do gestor municipal.

A investigação sobre os benefícios ambientais, sociais e econômicos percebidos com a certificação em cada país apresenta é demonstrada a seguir. Para os benefícios ambientais, o resultado geral (Gráfico 5) aponta em primeiro lugar a melhora geral na limpeza da praia; em segundo lugar, a melhoria na qualidade da água de banho; e, em terceiro, a recuperação de áreas protegidas.

Gráfico 5: Resultado geral dos benefícios ambientais

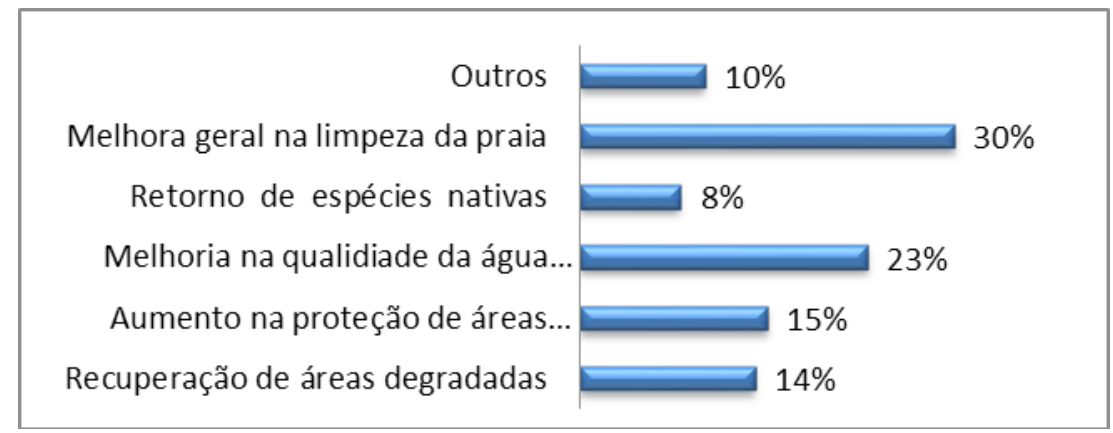

Fonte: Autores (2013). 
Comparativamente, ao observar os resultados da pesquisa Blue Flag Survey 2011, observa-se que $72 \%$ dos respondentes afirmaram acreditar que o Programa Bandeira Azul traz benefícios ambientais para o lugar, a maioria citando a limpeza geral do local (BLUE FLAG, 2011). Neste sentido, Zielinski e Cano (2014) constataram que os esquemas de certificação de praias na América Latina abarcam, principalmente, os aspectos ambientais e de qualidade turística. Da mesma forma, os resultados de um estudo realizado por Creo e Fraboni (2011) em todos os municípios com Bandeira Azul na Itália atestaram a validade do Programa Bandeira Azul na melhora integral da gestão da zona costeira, promovendo a incorporação de questões ambientais nos processos de tomada de decisão das autoridades locais e seus parceiros.

Porém, é possível verificar situações de contraposição em relação à centralidade da questão ambiental, como no estudo realizado por Mir-Gual et al. (2015), o qual foi voltado para as praias da Espanha outorgadas com a Bandeira Azul, mas com elevada ocupação humana e artificialização. Constataram que, neste caso, a outorga não se relaciona com a conservação do ambiente natural, mas apenas com os serviços existentes e disponibilizados para os seus usuários. Com base nesta constatação, os autores observam que a outorga deveria ser divulgada não como rótulo ecológico, mas como certificação de qualidade dos serviços oferecidos aos banhistas em praias urbanizadas.

Quantoaos benefíciossociais percebidos pelosoperadoresnacionais, o Gráfico 6 apresenta o resultado geral das escolhas, destacando-se em primeiro lugar a melhora na infraestrutura, seguida do advento da educação ambiental e da mudança de comportamento pela conservação. Especialmente, com a educação ambiental, tem-se a condição de promover uma mudança no comportamento proativo dos usuários, tanto em relação à conservação do ambiente natural da praia como em relação ao bom uso da infraestrutura instalada para servi-los. De acordo com Choi e Sirakaya (2006), programas de educação e informação são também muito importantes para garantir interpretações mais precisas sobre um destino. Os principais objetivos da educação consistem em aumentar a consciência dos visitantes e interessados sobre a natureza frágil do ambiente em determinada comunidade, tanto em relação aos ambientes naturais como 
em relação aos construídos e, assim, mudar o comportamento e a atitude dos tais visitantes e interessados.

Gráfico 6: Resultado geral dos benefícios sociais

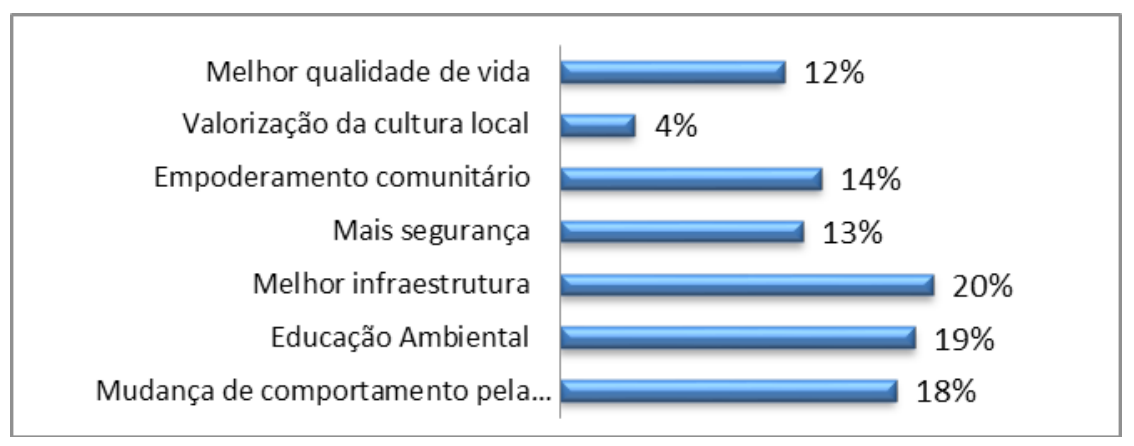

Fonte: Autores (2013).

Consequentemente, o Programa Bandeira Azul fortalece a capacidade competitiva de uma praia e, segundo a ABAE (2012), melhora também a imagem de todo o país como destino turístico, ao mesmo tempo em que proporciona a melhoria de vida dos residentes e visitantes, além de fomentar a adequação da oferta turística ao nível dos empreendimentos e dos serviços prestados nos balneários.

Dessa forma, enfatiza-se que os benefícios sociais trazem, junto com os benefícios econômicos, uma valorização do ambiente costeiro como destino turístico e, ainda, fortalecem as comunidades nele inseridas. No entanto, este poderá ser ainda um pressuposto sujeito à confirmação diante de uma realidade global, na medida em que se constatou que, no caso da América Latina, segundo Zielinskie e Cano (2014), os esquemas de certificação de praias são pouco participativos e a comunidade local é vista mais como objeto do que como sujeito no processo. Contudo, houve uma ressalva ao Programa Bandeira Azul considerado, comparativamente com os demais esquemas de certificação de praias, o que mais se aproximou da condição de uma certificação participativa.

Ainda no âmbito da dimensão social deste programa, Lucrezi et al. (2015), respaldados em pesquisa realizada junto a gestores e banhistas em praias da África do Sul, propuseram uma nova estrutura de educação para o Blue Flag, contendo etapas associadas com comunicação e interpretação na praia, focando os seus ecossistemas; a adoção da interdisciplinaridade (psicologia, educação, 
comunicação, sociologia,...) como estratégia de educação; a transformação de turistas de natureza em ecoturistas; e a educação preparatória das pessoas que serão responsáveis por esses programas. Depreende-se, então, que a consolidação e o alcance social do Programa Bandeira Azul é um desafio permanente e com facetas próprias a cada localidade, cujas condições e circunstâncias próprias vão determinar a amplitude deste alcance.

O aumento da infraestrutura específica vai também aumentar a oferta de empregos e esquentar a economia local, podendo até contribuir para a diminuição da criminalidade (LEMOS, 2005). Assim, segundo Bernardi (2010), é importante valorizar os investimentos em infraestrutura, tanto geral como específica, desde que sejam planejados em consonância com a realidade ambiental e social do lugar. Estes investimentos trazem benefícios bastante significativos para a atividade turística e para as comunidades locais.

Por fim, apresentam-se os benefícios econômicos percebidos pelos operadores nacionais do programa. De acordo com o resultado geral exposto no Gráfico 7, a melhora na qualidade dos serviços turísticos, o aumento do fluxo turístico e a mudança positiva no perfil do turista foram, respectivamente, os aspectos mais destacados.

Gráfico 7: Resultado geral dos benefícios econômicos

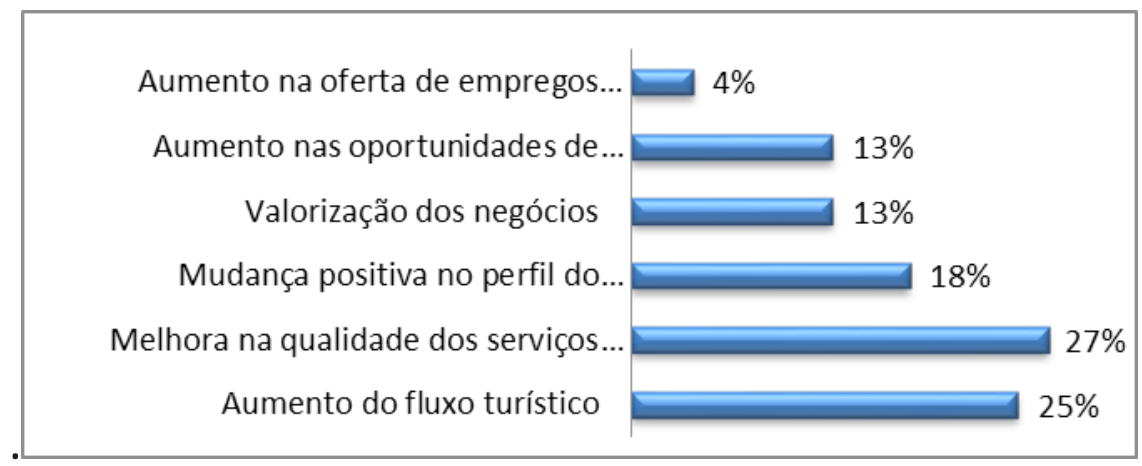

Fonte: Autores (2013).

Este cenário sugere o entendimento de que a melhora na qualidade dos serviços turísticos pode também ser uma combinação do aumento do fluxo turístico com a mudança positiva no perfil do turista que, assim, acaba impondo a necessidade de melhorar o padrão dos serviços. Ao oferecer um serviço de 
melhor qualidade, os empreendimentos podem também se beneficiar de uma valorização dos seus produtos e serviços, além de contratar mão de obra mais qualificada e, ainda, proporcionar treinamento para sua equipe de confiança, promovendo uma melhora salarial.

Comparativamente, a pesquisa Blue Flag Survey 2011 revela que 27\% dos respondentes consideraram que a certificação promoveu um aumento no fluxo de turistas nacionais e 57\% não souberam dizer se houve ou não um aumento. É importante observar também que $26 \%$ dos entrevistados perceberam um aumento nas chegadas de turistas internacionais e 55\% não souberam afirmar se houve ou não um aumento destes turistas (BLUE FLAG, 2011). Este panorama demonstra a dificuldade em atribuir o aumento da visitação somente para a certificação Bandeira Azul, pois, na maioria das vezes, os aspectos que influenciam uma viagem não são claramente evidenciados e também podem ser múltiplos. De qualquer forma, a pesquisa citada revelou que $77 \%$ dos entrevistados acreditam que a certificação trouxe benefícios econômicos de forma geral e em particular para o desenvolvimento do comércio.

Neste aspecto, Kaupilla, Saarinen e Leinonen (2009) observam que, para os governantes, o maior interesse em turismo sempre foi pelas perspectivas positivas de crescimento econômico para as suas regiões, por meio do aumento na oferta de empregos e da diversificação da economia local. De qualquer forma, evidencia-se o apelo de marketing do Bandeira Azul, tal como o constatado na Ucrânia por Radchenko e Aleyev (2011), onde, segundo os autores, muitos municípios interessam-se pelo programa também devido a este apelo.

Ao analisar todos os benefícios indicados pelos operadores nacionais do Programa Bandeira Azul, pode-se observar que existe uma estreita interrelação entre eles. É possível aqui afirmar que os benefícios ambientais, como limpeza, balneabilidade e conservação, são também atrativos para os visitantes e, portanto, trazem benefícios econômicos, como: melhora na qualidade dos serviços, aumento no fluxo turístico e mudança positiva no perfil de consumo do turista. Estes benefícios econômicos, por sua vez, influenciam na promoção dos benefícios sociais, como melhora na infraestrutura, educação ambiental e mudança de comportamento. Estes, por sua vez, possibilitam a oportunidade 
de se assegurar os benefícios ambientais, formando um ciclo virtuoso de mudanças com resultados positivos na gestão das praias certificadas.

Não obstante esta já consolidada percepção por parte dos gestores do Programa Bandeira Azul, no tocante à literatura científica, o que se constata é uma ainda limitada bibliografia contemporânea voltada para a abordagem empírica deste programa. Neste sentido e de forma panorâmica, é possível constatar que esta literatura apresenta, via de regra, abordagens mais amplas e não focadas em praias específicas. Encontram-se, então, estudos discutindo a implementação e as perspectivas do Programa Bandeira Azul na Ucrânia (RADCHENKO; ALEYEV, 2011); caracterizando o programa como exemplo de manejo sustentável de destinações turísticas costeiras na Itália (CREO; FRABONI, 2011); situando o programa no contexto de outros esquemas de certificação de praias turísticas na América Latina, com enfoque nos seus componentes socioculturais e participativos (ZIELINSKI; CANO, 2014), neste caso merecendo um destaque positivo em relação aos demais programas; inserindo o programa no âmbito do gerenciamento de praias e dos banhistas na África do Sul (LUCREZI et al. 2015), onde se verificaram falhas de comunicação dos gestores para com os banhistas usuários, com reflexo negativo na educação ambiental; ou, ainda, relacionando o Bandeira Azul num estudo voltado para a motivação dos visitantes de praias da Irlanda, País de Gales, Turquia e EUA, o qual revelou a pouca influência dos selos e das certificações das praias, incluindo o Bandeira Azul, na sua preferência por parte dos mesmos (McKENNA et al. 2011).

\section{CONSIDERAÇÕES FINAIS}

Com uma abrangência e inserção mundiais cada vez maior, o Programa Bandeira Azul surgiu para incentivar a adoção de boas práticas na gestão de praias e marinas. Desde a década de 1980, o Bandeira Azul vem promovendo a sensibilização dos gestores e dos usuários de praias sobre a importância ambiental dos destinos costeiros. Adicionalmente, além de promover melhores práticas que beneficiam o meio ambiente, o Programa Bandeira Azul promove também benefícios sociais e econômicos. 
Assim, ao expor que um ambiente saudável é seu melhor benefício ambiental, os entrevistados compreendem que suas ações são causa e consequência do ambiente em que vivem. Esta compreensão deve ser sempre alimentada por ações de educação ambiental nas praias certificadas, colaborando para a formação de um público mais consciente e cuidadoso com o meio ambiente. Quanto aos aspectos econômicos, percebeu-se que a certificação Bandeira Azul promove um aumento no fluxo de turistas, seguido por uma mudança positiva no perfil do visitante, que traz como consequência uma melhora na qualidade dos produtos e dos serviços turísticos. Esta evolução resulta em um produto turístico comercialmente diferenciado. Forma-se, portanto, um ciclo virtuoso desencadeado pela sucessão dos benefícios ambientais, sociais e econômicos advindos da boa gestão das praias certificadas.

Por outro lado, pode-se constatar que as principais dificuldades mencionadas pelos representantes dos operadores nacionais de todos os países para o crescimento do programa são reflexos notadamente da limitação de recursos financeiros e da falta de vontade política. Já na literatura, alguns posicionamentos críticos ficaram evidentes e devem ser considerados para o aperfeiçoamento do Programa Bandeira Azul. Entre eles, o fato de que em praias mais urbanizadas a ênfase acaba recaindo apenas nos serviços disponibilizados para os usuários, ficando a conservação ambiental em segundo plano; ou de que a comunidade local é vista mais como objeto do que como sujeito no processo ou, ainda, do uso deliberado da outorga Bandeira Azul como instrumento de marketing do destino, secundarizando os princípios maiores do programa, que são a qualificação ambiental das praias e a educação de usuários residentes e turistas.

Como já se antecipou quando da introdução deste artigo, mesmo no âmbito internacional, sempre existiu uma carência de dados públicos sobre os benefícios do Programa Bandeira Azul, ainda que, no domínio das organizações que o desenvolvem, circulassem os depoimentos sobre os benefícios do programa. Porém estes depoimentos não constavam em pesquisas e registros formais. Diante deste problema, os resultados aqui apresentados já podem colaborar com elementos para a comparação e a discussão entre as distintas situações relacionadas a cada realidade nacional do programa. 
Desta forma, espera-se que os resultados desta pesquisa, mesmo que empiricamente circunscritos ao âmbito dos gestores nacionais do programa, possam contribuir para suprir informações sobre os benefícios e as limitações do Bandeira Azul. Assim, gestores municipais e empresários poderão encontrar uma base para a iniciativa de investirem financeira e politicamente na busca pela certificação Bandeira Azul, também como uma estratégia para a superação ou enfrentamento de um problema tão antigo como recorrente na maioria das praias, especialmente em países em desenvolvimento, que é o saneamento ambiental e o não comprometimento de seus usuários com proteção e valorização deste recurso turístico com tamanha importância social.

Finalmente, para a satisfatória realização desta pesquisa, há que se destacar a viabilização do acesso à documentação do Programa Bandeira Azul e das praias inscritas, bem como dos contatos com a coordenação internacional e com os demais países participantes do programa. Tal fato ocorreu devido ao envolvimento direto de um dos autores na coordenação do programa no Brasil.

\section{REFERÊNCIAS}

ARAUJO, Maria Christina Barbosa de. Praia da Boa Viagem, Recife - PE: Análise Sócio-Ambiental e Propostas de Ordenamento. Universidade Federal de Pernambuco. Recife, 2008.

ARIZA, Eduard; JIMÉNEZ José A. e SARDÁ Rafael. A critical assessment of beach management on the Catalan coast. Ocean \& Coastal Management, ed. 51, p. 141-160, 2008.

ASOCIACIÓN DE EDUCACIÓN AMBIENTAL Y DEL CONSUMIDOR - ADEAC. BF numbers history in countries. Disponível em: <http://www.adeac.es/sites/default/files/archivos/ BF\%20numbers\%20history\%20in\%20countries.pdf>. Acesso em: 14 de Junho de 2013

ASSOCIAÇÃO BANDEIRA AZUL DA EUROPA - ABAE. Bandeira Azul: há 25 anos a trabalhar por um desenvolvimento sustentável. Lisboa, 2012

BERNARDI, L. P. Programa Bandeira Azul: O Processo para a certificação de praias no contexto do turismo sustentável, aplicado a Praia de Jurerê Internacional Florianópolis, SC. TCC. Balneário Camboriú: UNIVALI, 2010.

BERNARDI, L. P. A Sustentabilidade no Turismo de Sol e Praia: Os Benefícios do Programa Bandeira Azul e o caso da Praia do Tombo, Guarujá-SP. Dissertação. Programa de Pós- 
ISSN: 1983-7151

graduação em Turismo e Hotelaria. Universidade do Vale do Itajaí. Balneário Camboriú, Santa Catarina, Brasil. 2013. 162 p.

BIEN, A. A simple user's guide to certification for sustainable tourism and ecotourism. THE ECOTOURISM SOCIETY (TIES), Washington DC, 2003:

BLUE FLAG. Blue Flag 2011 Survey for Beach and Marina Managers. Disponível em: $<$ http://www.blueflag.org/service-menu/internal-pages/meetings/results-of-bf-survey2011 >. Acesso em: 06 Junho 2013.

BLUE FLAG, Biodiversity key to marine protection, says meeting of Blue Flag operators. Disponível em: http://www.blueflag.org/service-menu/news/biodiversity-key-to-marineprotection-says-meeting-of-blue-flag-operators. Acesso em: 10 de Junho de 2013.

BLUE FLAG, Environmental Education Activities Book. Foundation for Environmental Education, Copenhagen, 2011.

BLUE FLAG, Increasing quality of Blue Flag sites worldwide acknowledged by International Jury, Disponível em: http://www.blueflag.org/service-menu/news/increasingquality-of-blue-flag-sites-worldwide-acknowledged-by-international-jury. Acesso em: 10 de Junho de 2013.

BLUE FLAG. Inquiry on Blue Flag in France. Disponível em: http://www.blueflag.org/ service-menu/internal-pages/national-documents. Acesso em: 06 de Junho de 2013.

BLUE FLAG, The Blue Flag Eco-label for Beaches and Marinas Disponível em: http://www. blueflag.org/Materiale/Publication-downloads/BlueFlagBrochure2007. Acesso em: 06 de Novembro de 2012.

BLUE FLAG. Blue Flag. Disponível em: http://www.blueflag.org/. Acesso em: 27 de agosto de 2015.

BRASIL. Ministério do Turismo. Pesquisa de Hábitos de Consumo do Turismo Brasileiro 2009. Governo Federal, Brasília, 2009. Disponível em: <http://www.turismo.gov.br/export/ sites/default/turismo/noticias/todas_noticias/Noticias_download/13.11.09_Pesquisa_ Hxbitos_2009.pdf>. Acesso em: 12 de Agosto de 2012.

BUCKLEY, Ralf. Tourism and Biodiversity: Land-use, planning and impact assessment. The Journal of Tourism Studies. Vol. 10, n 2 p.47-99, 1999

BUCKLEY, Ralf. Tourism ecolabels. Annals of Tourism Research, v.29, n.1, p. 183-208, 2002. 
CENTER FOR RESPONSIBLE TRAVEL - CREST. The Case for Responsible Travel: Trends and Statistics. Disponível em: http://www.responsibletravel.org/resources/documents/ reports/Crest_RTI_TrendStats_email1_4\%20\%282_Small\%29.pdf. Acesso em: 28 de Fevereiro de 2013.

CHOI, HwanSuk Chris e SIRAKAYA, Ercan. Sustainability Indicators for Managing Community Tourism. Tourism Management. N 27,1274-1289. Elsevier, 2006.

CREO, Carla; FRABONI, Claudia. Awards for the Sustainable Management of Coastal Tourism Destinations: The Example of the Blue Flag Program. Journal of Coastal Research, Special Issue. n. 61, p.378-381, 2011.

FONTELES, José Osmar. Turismo e Impactos Socioambientais. São Paulo: Aleph, 2004.

GÂNDARA, J. M.; MENDES, J. C.; MOITAL M.; RIBEIRO, F. N. S. ; SOUZA, I. J.; GOULART, L. A. A qualidade da experiência na visitação dos destinos turísticos.p. 383-396) In: BENI, M. C. (Organizador) Turismo: Planejamento Estratégico e Capacidade de Gestão. Barueri, SP: Manole, 2012.

FONT, Xavier. Environmental certification in tourism and hospitality: progress, process and prospects. Tourism Management, v. 23, Issue 3, p. 197- 205, 2002.

FOUNDATION FOR THE ENVIRONMENTAL EDUCATION (FEE), Handbook 2013. Copenhagen, 2013.

FOUNDATION FOR THE ENVIRONMENTAL EDUCATION (FEE), Handbook for Member Organizations. Copenhagen, 2008.

FOUNDATION FOR THE ENVIRONMENTAL EDUCATION (FEE). 20 Years of Blue Flag. Copenhagen, Dinamarca: 2007

FOUNDATION FOR THE ENVIRONMENTAL EDUCATION (FEE). About FEE. Disponível em: http://www.fee-international.org/en/Menu/About+FEE. Acesso em: 04 de Novembro de 2012.

FOUNDATION FOR THE ENVIRONMENTAL EDUCATION (FEE). Annual Report 2008. Norwick, England: 2009

FOUNDATION FOR THE ENVIRONMENTAL EDUCATION (FEE). Our history. Disponível em: < http:// www.fee-international.org/en/Menu/Our+history>. Acesso em: 06 de Novembro de 2012.

HALL, C. M. Planejamento Turístico: políticas, processos e relacionamentos. 2. ed. São Paulo: Contexto, 2004. 
INSTITUTO AMBIENTAL RATONES (IAR). A nossa equipe. Florianópolis, 2010. Disponível em: http://www.iarbrasil.org.br/. Acesso em: 20 de Outubro de 2012.

INSTITUTO AMBIENTAL RATONES (IAR). Programa Bandeira Azul. Florianópolis, 2010. Disponível em: http://webpagebrasil.com.br/sites/admin/000049/arquivos/files/ AdesãoPraias.pdf. Acesso em: 20 de Outubro de 2012.

INSTITUTO AMBIENTAL RATONES (IAR). Quem somos. Florianópolis, 2010. Disponível em: http://www.iarbrasil.org.br/ Acesso em: 20 de Outubro de 2012.

INSTITUTO AMBIENTAL RATONES (IAR). Programa Bandeira Azul Praias: critérios e notas explicativas. Florianópolis, 2010. Disponível em: http://webpagebrasil.com.br/sites/ admin/000049/arquivos/files/CRITERIOS\%20BANDEIRA\%20AZUL\%20PRAIAS.pdf. Acesso em: 20 de Outubro de 2012.

KAUPILLA, Penkka; SAARINEN, Jarkko LEINONEN, Riikka. Sustainable Tourism ad Regional Development in Peripheries: A Nordic View. Scandinavian Journal of Hospitality and Tourism, vl. 9, n 4, p. 424 - 435, 2009.

LAI, Kun; LI, Yiping; FENG, Xuegang. Gap between tourism planning and implementation: A case of China. Tourism Management, 27, 1171-1180, 2006.

LEMOS, Leandro de. $\mathbf{O}$ valor turístico na economia da sustentabilidade. São Paulo: Aleph, 2005.

LUCREZI, Serena; SAAYMAN, Melville; MERWE, Peet Van der. Managing beaches and beachgoers: lessons from and for the Blue Flag award. Tourism Management, v.48, June p. 211-230, 2015,

MCKENNA, John; WILLIAMS Allan T; COOPER, J. Andrew G. Blue Flag or Red Herring: do beach awards encourage the public to visit beaches? Tourism Management, v. 32, Issue 3, p. 576-588, 2011.

MIR-GUAL, M.; PONS, G.X.; MARTÍN-PRIETO, J.A; RODRÍGUEZ-PEREA, A. A critical view of the Blue Flag beaches in Spain using environmental variables. Ocean \& Coastal Management, v.105, March, p. $106-115,2015$.

ORGANIZAÇÃO MUNDIAL DO TURISMO (OMT). Colocação no mundial de viagens e turismo, pacotes de estímulo à economia verde. Disponível em: <www.world-tourism. org/>. Acesso 03 abril 2012. 
PNUMA- Programa das Nações Unidas para El Medo Ambiente; OMT- ORGANIZACIÓN MUNDIAL DEL TURISMO. Por um Turismo más Sostenible: guia para responsables políticos. España, 2006. Disponível em .<http://www.unep.fr/shared/publications/pdf/DTIx0884xPATourismPolicyES.pdf>. Acesso em: maio de 2013.

RADCHENKO, Victoria; ALEYEV, Modest. Blue Flag Program Implementation Prospective in Ukraine. Journal of Coastal Research, Special Issue, n. 61, p. 52-59, 2011.

RAINFOREST ALLIANCE. Practical steps for marketing tourism certification. Disponível em: <http://www.rainforest-alliance.org/tourism/documents/practical_steps.pdf> Acesso em: 22 de Abril de 2012.

RAINFOREST ALLIANCE. Certification, Verification and Validation Services. Disponível em: <http://www.rainforest-alliance.org/certification.cfm?id=about> Aceso em: 28 de Março de 2012.

VERA REBOLLO, J. Fernando Vera e IVARS BAIDAL, Josep A. Ivars. Measuting Sustainability in a Mass Tourist Destination: Pressures, Perceptions and Policy Responses in Torrevieja, Spain. Journal of Sustainable Tourism. v. 11, n. 2 \& 3, 2003.

RUSCHMANN; D. V. de M.; ROSA, R. G.; E WEIDGENANT, P. J. Z. Sustentabilidade como estratégia de desenvolvimento: Ilha de Porto Belo, SC. (p. 811-841). In: Philippi Jr, A.; RUSCHMANN, D.V. de M. (Editores) Gestão Ambiental e Sustentabilidade do Turismo. Barueri, SP: Manole, 2010.

WELFORD, Richard. Environmental Strategy and Sustainable Development: the corporate challenge for the $21^{\text {st }}$ Century. Routledge: Londres, 1995.

WORLDWIDE FUND FOR NATURE (WWF), A Strategic Environmental Assessment of Fiji's Tourism Development Plan. Fiji. 2003.

WORLDWIDE FUND FOR NATURE (WWF-BRASIL), 2001, Certificação do Turismo, lições mundiais e recomendações ao Brasil. vol. 9, Brasília, WWF.

WORLDWIDE FUND FOR NATURE. Certificação em Turismo: lições mundiais e recomendações para o Brasil. Coordenação Sérgio Salazar Salvati. Série Técnica, v. ix, WWFBRASIL, Brasília, 2001-b.

ZIELINSKI, Seweryn; CANO, Marlenny Díaz. Los esquemas de certificacion de playas turisticas en America Latina: evaluación del componente socio-cultural y el nivel participativo. Estudios y Perspectivas en Turismo, v. 23, n. 1, p. 156 - 175, 2014 